\title{
THE CONSERVATIVE TREATMENT OF COMPLETE TEARS OF THE ANTERIOR CRUCIATE LIGAMENT IN SKELETALLY IMMATURE PATIENTS
}

\author{
HIROSHI MIZUTA, KENJI KUBOTA, MINORU SHIRAISHI, YUTAKA OTSUKA, \\ NORIYOSHI NAGAMOTO, KATSUMASA TAKAGI
}

From Kumamoto University School of Medicine, Japan

We describe the results of conservative treatment for complete midsubstance tears of the anterior cruciate ligament (ACL) in 18 skeletally immature patients, followed for a minimum of 36 months. Six patients had an $A C L$ reconstruction during the follow-up period and were assessed immediately before their operation. The average time from initial injury to evaluation was 51 months.

All patients had symptoms when reviewed. The modified Lysholm knee score showed one excellent result, one good, eight fair, and eight poor with a mean score of 64.3. Only one patient had returned to her preinjury level of athletics. Secondary meniscal tears were confirmed in six patients, and three more had the clinical signs of a tear at follow-up. Radiological evidence of degenerative changes was found in 11 of the 18 patients.

We conclude that the results of non-operative treatment for ACL injuries in this age group are poor and not acceptable.

J Bone Joint Surg [Br] 1995;77-B:890-4.

Received 27 September 1994; Accepted afier revision 14 March 1995

H. Mizuta, MD, DMSc, Associate Professor

K. Kubota, MD, Lecturer

M. Shiraishi, MD, Lecturer

Y. Otsuka, MD, Postgraduate Student

N. Nagamoto, MD, DMSc, Lecturer

K. Takagi, MD, DMSc, Professor and Chairman

Department of Orthopaedic Surgery, Kumamoto University School of

Medicine, 1-1-1 Honjo, Kumamoto 860, Japan.

Correspondence should be sent to Dr H. Mizuta.

O1995 British Editorial Society of Bone and Joint Surgery

$0301-620 \times / 95 / 61061 \$ 2.00$
Midsubstance tears of the anterior cruciate ligament (ACL) had been thought to be extremely rare in children and adolescents with open physes, because the ACL is normally stronger than physis or bone (DeLee and Curtis 1983). Recent studies have shown, however, that ACL injuries are more common in this age group than has been previously considered (Lipscomb and Anderson 1986; Eiskjaer, Larsen and Schmidt 1988; Engebretsen, Svenningsen and Benum 1988; Kannus and Järvinen 1988; McCarroll, Rettig and Shelbourne 1988; Angel and Hall 1989; Graf et al 1992; Vähäsarja, Kinnuen and Serlo 1993). This may be due to the increased number of younger participants in athletics and improvements in diagnosis. Little information is available on the natural history of these injuries in skeletally immature patients, although there have been small or shortterm studies of conservative treatment (Kannus and Järvinen 1987; McCarroll et al 1988; Angel and Hall 1989; Graf et al 1992).

We have reviewed the results of the non-operative treatment of ACL tears in 18 skeletally immature patients with a minimum follow-up of 36 months.

\section{PATIENTS AND METHODS}

Between 1985 and 1990, 18 patients ( 2 boys, 16 girls) with open physes were treated conservatively for complete midsubstance tears of the ACL sustained during sport (Table I). The average age at injury was 12.8 years (10 to 15$)$. Thirteen of the 18 patients were younger than 14 years. All presented with an acute haemarthrosis after injury, and the diagnosis was confirmed by arthroscopy within three months. Examination under anaesthesia before arthroscopy showed a positive Lachman sign and a positive pivot shift in all patients. None had clinical signs of other ligament injury. At arthroscopy meniscal tears were found in 13 patients. Four medial and two lateral menisci were partially removed and three medial menisci were repaired arthroscopically. One small partial tear of the medial meniscus and five tears in the posterior horn of the lateral meniscus were not repaired.

The three patients with meniscal repairs wore a long-leg cast for three weeks before beginning progressive movement. They were allowed partial weight-bearing at four weeks and full weight-bearing at six weeks. In the remain- 
Table I. Details of the 18 patients with midsubstance tears of the ACL

\begin{tabular}{|c|c|c|c|c|c|c|}
\hline Case & Sex & $\begin{array}{l}\text { Age at } \\
\text { injury } \\
(\mathbf{y r})\end{array}$ & $\begin{array}{l}\text { Cause of } \\
\text { injury }\end{array}$ & $\begin{array}{l}\text { Initial interval } \\
\text { to arthroscopy } \\
\text { (days) }\end{array}$ & $\begin{array}{l}\text { Meniscal injuries } \\
\text { at initial arthroscopy } \\
\text { and treatment* }\end{array}$ & $\begin{array}{l}\text { Subsequent surgery } \\
\text { (months after initial injury) }\end{array}$ \\
\hline 1 & $\mathbf{F}$ & 10 & Basketball & 9 & & \\
\hline 2 & $\mathbf{F}$ & 10 & Volleyball & 37 & & \\
\hline 3 & $\mathbf{F}$ & 14 & Running high jump & 76 & MM repair & \\
\hline 4 & $\mathbf{F}$ & 13 & Volleyball & 35 & & \\
\hline 5 & $\mathbf{F}$ & 13 & Gymnastics & 15 & & \\
\hline 6 & $\mathbf{F}$ & 14 & Volleyball & 4 & MM and LM tears; no treatment & \\
\hline 7 & $\mathbf{F}$ & 13 & Gymnastics & 4 & LM tear; no treatment & \\
\hline 8 & $\mathbf{F}$ & 13 & Volleyball & 12 & MM repair & \\
\hline 9 & $\mathrm{~F}$ & 14 & Basketball & 30 & & Partial LM resection (28) \\
\hline 10 & $\mathbf{M}$ & 13 & Gymnastics & 60 & MM repair & \\
\hline 11 & $\mathbf{F}$ & 14 & Basketball & 28 & Partial MM resection & \\
\hline 12 & $\mathbf{F}$ & 12 & Basketball & 9 & $\begin{array}{l}\text { Partial MM resection, LM tear; } \\
\text { no treatment }\end{array}$ & \\
\hline 13 & $\mathbf{F}$ & 15 & Volleyball & 12 & LM tear; no treatment & ACLR†, partial LM resection (10) \\
\hline 14 & $\mathbf{M}$ & 13 & Judo & 20 & Partial MM resection & ACLR (28) \\
\hline 15 & $\mathbf{F}$ & 12 & Basketball & 2 & Partial LM resection & ACLR, MM repair (23) \\
\hline 16 & $\mathbf{F}$ & 13 & Basketball & 9 & LM tear; no treatment & ACLR, partial MM resection (36) \\
\hline 17 & $\mathbf{F}$ & 12 & Basketball & 30 & Partial LM resection & ACLR, MM repair (58) \\
\hline 18 & $\mathbf{F}$ & 13 & Gymnastics & 28 & Partial MM resection & ACLR, partial MM resection (72) \\
\hline
\end{tabular}

Table II. Findings at follow-up examination in 18 patients

\begin{tabular}{|c|c|c|c|c|c|c|c|c|c|c|c|c|}
\hline \multirow[b]{2}{*}{ Case } & \multirow[b]{2}{*}{$\begin{array}{l}\text { Follow-up } \\
\text { (mth) }\end{array}$} & \multicolumn{3}{|c|}{ Lysholm score } & \multirow{2}{*}{$\begin{array}{l}\text { Level of } \\
\text { sports } \\
\text { activity } \dagger\end{array}$} & \multicolumn{4}{|c|}{ Physical findings } & \multicolumn{3}{|c|}{ Isokinetic muscle torque } \\
\hline & & $\begin{array}{l}\text { Instability } \\
\text { (max 25) }\end{array}$ & $\begin{array}{l}\text { Pain } \\
(\max 25)\end{array}$ & $\begin{array}{l}\text { Total* } \\
(\max 100)\end{array}$ & & $\begin{array}{l}\text { Joint-line } \\
\text { tenderness }\end{array}$ & $\begin{array}{l}\text { McMurray } \\
\text { sign }\end{array}$ & $\begin{array}{l}\text { Valgus } \\
\text { laxity }\end{array}$ & $\begin{array}{l}\text { Varus } \\
\text { laxity }\end{array}$ & $\begin{array}{l}\text { Quadriceps } \\
\text { ratio (\%) }\end{array}$ & $\begin{array}{l}\text { Hamstring } \\
\text { ratio }(\%)\end{array}$ & $\begin{array}{l}\text { Radiological } \\
\text { score } \neq\end{array}$ \\
\hline 1 & 45 & 25 & 20 & $95(E)$ & 0 & & & & & 104 & 121 & 0 \\
\hline 2 & 56 & 10 & 15 & $71(F)$ & 3 & & & & & 90 & 92 & 0 \\
\hline 3 & 36 & 10 & 10 & $48(P)$ & 3 & $+($ med $)$ & + & & & 78 & 90 & 0 \\
\hline 4 & 38 & 10 & 15 & $67(F)$ & 3 & $+($ med $)$ & + & & & 80 & 95 & 0 \\
\hline 5 & 48 & 5 & 15 & $66(F)$ & 3 & & & & & 83 & 98 & 2 \\
\hline 6 & 47 & 10 & 15 & $69(F)$ & 1 & $+($ med $)$ & & & & 78 & 91 & 2 \\
\hline 7 & 53 & 10 & 15 & $57(P)$ & 4 & $+($ med $)$ & + & & & 99 & 98 & 1 \\
\hline 8 & 63 & 10 & 20 & $71(F)$ & 4 & & & + & & 107 & 72 & 1 \\
\hline 9 & 63 & 10 & 5 & $39(P)$ & 3 & + (lat) & & & & 62 & 98 & 3 \\
\hline 10 & 67 & 15 & 20 & $85(G)$ & 1 & & & & & 92 & 96 & 1 \\
\hline 11 & 69 & 10 & 20 & $71(F)$ & 4 & $+($ med $)$ & & & & 85 & 81 & 3 \\
\hline 12 & 99 & 15 & 15 & $75(F)$ & 4 & & & + & & 84 & 92 & 2 \\
\hline 13 & 10 & 15 & 15 & $76(F)$ & 1 & & & & & 90 & 93 & 0 \\
\hline 14 & 23 & 10 & 15 & $48(P)$ & 1 & & & & & 78 & 93 & 2 \\
\hline 15 & 28 & 15 & 5 & $57(P)$ & 3 & $+($ med $)$ & + & & & 89 & 88 & 0 \\
\hline 16 & 36 & 10 & 15 & $52(\mathrm{P})$ & 1 & $+($ med $)$ & + & & + & 78 & 108 & 0 \\
\hline 17 & 58 & 10 & 20 & $61(P)$ & 1 & $+($ med $)$ & + & + & & 72 & 89 & 2 \\
\hline 18 & 72 & 5 & 15 & $49(P)$ & 3 & $+($ med $)$ & + & & & 81 & 96 & 2 \\
\hline
\end{tabular}

* $E$ = excellent; $G=$ good; $F=$ fair; $P=$ poor

$\dagger$ see text

$\ddagger$ see text 
ing patients active movement and weight-bearing were allowed as tolerated. Immediately after operation all patients began progressive quadriceps and hamstring strengthening exercises. Return to sport was allowed when the strength in the quadriceps and hamstring muscles had reached $90 \%$ of that in the contralateral leg when measured on a Cybex II dynamometer (Lumex Inc, Ronkonkoma, New York), but patients who had meniscal repairs were not allowed to participate in sport until six months after operation. A functional knee brace was recommended during participation in sport.

Follow-up evaluation. A detailed questionnaire was completed and a physical examination, measurement of muscle strength with a Cybex II dynamometer, and radiological evaluation were carried out (Table II). The subjective assessment of symptoms and function in the injured knee was done using a modified Lysholm knee score (Tegner and Lysholm 1985), based on a 100-point system. An excellent result scored 95 to 100 points, good 84 to 94 , fair 65 to 83 , and poor $<65$ points. The level of sports activity was graded according to Feagin and Blake (1983) as follows: 0, equal performance at the same sports as before injury; 1, a lower level of performance at the same sports; 2 , active, but in different sports; 3 , significant limitation of sports activity; and 4, no sports. The range of motion, the presence of an effusion in the knee, joint-line tenderness, the McMurray test, tests for clinical instability including the Lachman, pivot-shift and varus and valgus stress tests, were carried out. Quadriceps and hamstring strength was measured with a Cybex II dynamometer and the peak torque at a speed of $60 \%$ sec was determined. Both knees were tested and the ratio of the injured to the uninjured leg was calculated. Standing anteroposterior and lateral radiographs of both knees were obtained and the presence of degenerative changes assessed according to Fairbank's criteria (Fairbank 1948).

\section{RESULTS}

All patients were followed up for a minimum of 36 months after injury. During this period, six underwent ACL reconstruction because of symptoms of persisting instability. They were assessed immediately before the reconstruction at an average time from injury of 38 months (10 to 72$)$. At ACL reconstruction, four medial and one lateral meniscal tears were identified in five patients. Three underwent partial meniscectomies and two had meniscal repairs. The 12 patients who did not require a reconstruction were followed up for an average of 57 months (36 to 99). One of these patients had a further arthroscopy and a partial meniscectomy for a fresh tear of the lateral meniscus 28 months after her initial injury. Details of the results are given in Table II.

Subjective evaluation. All patients had symptoms, with instability and pain being the most common. Seventeen experienced 'giving way': four complained of giving way frequently during severe exertion, 11 occasionally in daily activities, and two often in daily activities. All 18 patients complained of pain: five reported slight pain during severe exertion, ten had marked pain during severe exertion, one marked pain on moderate exertion, and two marked pain on slight exertion. Four patients had occasional locking and in six it occurred frequently. Swelling on severe exertion was present in nine patients, and constant swelling in two. Two had a slight limp. Nine had slight difficulty with stairclimbing, and four with squatting. The total knee score using the modified Lysholm rating system ranged from 39 to 95 , with an average of 64.3 . Based on this scale, one patient had an excellent result, one good, eight fair, and eight poor.

Activity level. Only one of 18 patients returned to her previous level of athletic activity. Thirteen performed at a lower level, and four were unable to play sports. Of the 16 patients participating in school athletics before their injury, ten were unable to continue in the same sport due to recurrent instability.

Physical examination. No patient had loss of movement or an effusion when examined at follow-up. The Lachman test and the pivot-shift test were positive in all. The varus or valgus test at $30^{\circ}$ flexion of the knee, both of which were originally negative, showed grade-1 laxity, with less than $5 \mathrm{~mm}$ of displacement compared with the uninjured knee (Hughston et al 1976) in three patients in valgus and one in varus. There was no laxity in full extension. Ten patients had medial or lateral joint-line tenderness, and seven had a positive McMurray sign. Four of the five patients who had new meniscal tears at the time of ACL reconstruction had joint-line tenderness and a positive McMurray sign.

Muscle power. The average strength ratio of the injured to the uninjured leg was $85 \%$ (62 to 107) for the quadriceps and $94 \%$ (72 to 121) for the hamstrings.

Radiological evaluation. Using Fairbank's criteria there was no demonstrable abnormality (grade 0 ) in seven patients. Squaring or flattening of the femoral condyles (grade 1) was seen in three, marginal osteophyte formation (grade 2) in six, and joint-space narrowing (grade 3) in two. None had frank osteoarthritis (grade 4). In the seven patients with a previous meniscectomy one was classified as grade 0 , four as grade 2 and two as grade 3 . In the 11 patients who had not undergone meniscectomy six were grade 0 , three were grade 1 and two grade 2 . Prior meniscectomy appeared to correlate with the incidence and severity of degenerative changes as seen on radiographs.

\section{DISCUSSION}

The outcome of non-operative treatment for ACL injuries in our skeletally immature patients was not acceptable, with fair or poor results in 16 of the 18 treated. Only one was able to resume activity at preinjury level. The remainder had to modify their activities because of instability, and six required late ACL reconstruction. Other authors have pub- 
lished similar findings. McCarroll et al (1988) described 16 young athletes with open physes who were treated conservatively for midsubstance tears of the ACL, with an average follow-up of 26 months. Seven had returned to athletics, but all experienced recurrent episodes of giving way or reinjury. Angel and Hall (1989) reported seven children and adolescents with complete midsubstance tears of the ACL which were not repaired; none was able to return to their preinjury level of athletics and secondary ACL reconstruction had been performed or planned in three. Graf et al (1992) had poor results with non-operative treatment in eight skeletally immature patients with acute, complete intrasubstance ACL tears. After their return to athletics, all had multiple episodes of giving way and seven required secondary ACL reconstruction.

Repeated episodes of giving way result in additional injuries to the menisci (Hart 1982; Hawkins, Misamore and Merritt 1986; Irvine and Glasgow 1992). In our study, secondary meniscal tears were confirmed by arthroscopy in six patients during the period of follow-up, and another three had clinical signs of meniscal tear, with both a positive McMurray sign and joint-line tenderness. Graf et al (1992) found secondary tears of the menisci during follow-up in seven of eight skeletally immature patients with ACL tears, and this high incidence of secondary tears is thought to be due to the marked degree of functional instability in the knees.

We recognise that rupture of the ACL rarely occurs as an isolated lesion without any associated damage to other ligamentous or capsular structures (Johnson et al 1992) but initially, when examined under anaesthesia, none of our patients showed valgus or varus laxity. At follow-up, four had mild laxity, presumably due to the stretching of secondary ligamentous restraints during follow-up (Odensten, Lysholm and Gillquist 1984; Hawkins et al 1986; Corrigan, Cashman and Brady 1992).

At an average of 51 months after injury there was radiological evidence of degeneration in 11 of 18 patients. Nine had only mild changes with squaring or flattening of the femoral condyles or marginal osteophyte formation, but two had a reduced joint space. Development of degenerative changes appeared to be associated with prior meniscectomy (Balkfors 1982; McDaniel and Dameron 1983; Satku, Kumar and Ngoi 1986). Previous studies (DeHaven 1985; Miller 1988; Ryu and Dunbar 1988) have shown that the risk of a retear in meniscal repair is higher in unstable ACL-deficient knees than in stable joints, but we believe that such a repair should still be performed even in unstable knees, especially in skeletally immature patients.

Sixteen of our 18 patients were girls. In Lipscomb and Anderson's report (1986), 21 of 24 patients were boys. In the study of McCarroll et al (1988), the number of boys and girls was exactly the same. As yet, no male or female predominance has been shown for ACL injuries in skeletally immature patients. The female predominance in our study may be due to our position as team physicians for several sports clubs in female junior high schools.

Of the 18 patients, 13 had recurrent giving way even in daily life, probably due to the high degree of activity in this age group and to their limited ability to modify their activities to avoid episodes of giving way. Some authors (McDaniel and Dameron 1983; Johnson et al 1992) have described a degree of correlation between the original laxity of the knee or strength of the thigh muscle and the functional instability after ACL injuries, but it is uncertain whether the relative looseness of the joints or weakness of muscle strength in this age group affects functional instability. The results of non-operative treatment in our patients were similar to those found in highly active adults (Kannus and Järvinen 1987; Barrack et al 1990).

Conservative treatment of ACL injuries in our skeletally immature patients was unsuccessful in preventing instability and progressive deterioration of the knee. Several recent studies (Lipscomb and Anderson 1986; McCarroll et al 1988; Andrews, Noyes and Barber-Westin 1994; Parker, Drez and Cooper 1994) have shown satisfactory results after intra-articular ACL reconstruction in this age group, with a very low incidence of growth disturbance. These reports are encouraging, but further studies are necessary to determine the method and optimal timing for surgical intervention and to evaluate the long-term results of such treatment.

No benefits in any form have been received or will be received from a commercial party related directly or indirectly to the subject of this article.

\section{REFERENCES}

Andrews M, Noyes FR, Barber-Westin SD. Anterior cruciate ligament allograft reconstruction in the skeletally immature athlete. Am J Sports Med 1994;22:48-54.

Angel KR, Hall DJ. Anterior cruciate ligament injury in children and adolescents. Arthroscopy 1989;5:197-200.

Balkfors B. The course of knee-ligament injuries. Acta Orthop Scand 1982;53 Suppl 198:7-99.

Barrack RL, Buckley SL, Bruckner JD, Kneisl JS, Alexander AH. Partial versus complete acute anterior cruciate ligament tears: the results of nonoperative treatment. $J$ Bone Joint Surg $[\mathrm{Br}]$ 1990;72-B:622-4.

Corrigan JP, Cashman WF, Brady MP. Proprioception in the cruciate deficient knee. J Bone Joint Surg [Br] 1992;74-B:247-50.

DeHaven KE. Meniscus repair in the athlete. Clin Orthop 1985;198:31-5.

DeLee JC, Curtis R. Anterior cruciate ligament insufficiency in children. Clin Orthop 1983;172:112-8.

Eiskjaer S, Larsen ST, Schmidt MB. The significance of hemarthrosis of the knee in children. Arch Orthop Trauma Surg 1988;107:96-8.

Engebretsen L, Svenningsen S, Benum P. Poor results of anterior cruciate ligament repair in adolescence. Acta Orthop Scand 1988;59:684-6.

Fairbank TJ. Knee joint changes after meniscectomy. $J$ Bone Joint Surg [Br] 1948;30-B:664-70.

Feagin JA Jr, Blake WP. Postoperative evaluation and result recording in the anterior cruciate ligament reconstructed knee. Clin Orthop 1983;172:143-7.

Graf BK, Lange RH, Fujisakj CK, Landry GL, Saluja RK. Anterior cruciate ligament tears in skeletally immature patients: meniscal pathology at presentation and after attempted conservative treatment. Arthroscopy 1992;8:229-33.

Hart JAL. Meniscal injury associated with acute and chronic ligamentous instability of the knee joint. J Bone Joint Surg [Br] 1982;64-B:119. 
Hawkins RJ, Misamore GW, Merritt TR. Follow-up of the acute nonoperated isolated anterior cruciate ligament tear. Am J Sports Med 1986; 14:205-10.

Hughston JC, Andrews JR, Cross MJ, Moschi A. Classification of knee ligament instabilities. Part I. The medial compartment and cruciate ligaments. J Bone Joint Surg [Am] 1976;58-A:159-72.

Irvine GB, Glasgow MMS. The natural history of the meniscus in anterior cruciate insufficiency: arthroscopic analysis. J Bone Joint Surg [Br] 1992;74-B:403-5.

Johnson RJ, Beynnon BD, Nichols CE, Renstrom PA. Current concepts review: the treatment of injuries of the anterior cruciate ligament. $J$ Bone Joint Surg [Am] 1992;74-A:140-51.

Kannus P, Järvinen $M$. Conservatively treated tears of the anterior cruciate ligament: long-term results. J Bone Joint Surg [Am] 1987; 69-A:1007-12.

Kannus P, Järvinen M. Knee ligament injuries in adolescents: eight year follow-up of conservative management. J Bone Joint Surg [Br] 1988; 70-B:772-6.

Lipscomb AB, Anderson AF. Tears of the anterior cruciate ligament in adolescents. J Bone Joint Surg [Am] 1986;68-A:19-28.
McCarroll JR, Rettig AC, Shelbourne KD. Anterior cruciate ligament injuries in the young athlete with open physes. Am J Sports Med 1988;16:44-7.

McDaniel WJ Jr, Dameron TB Jr. The untreated anterior cruciate ligament rupture. Clin Orthop 1983;172:158-63.

Miler DB Jr. Arthroscopic meniscus repair. Am J Sports Med 1988;16:315-20.

Odensten M, Lysholm J, Gillquist J. Suture of fresh ruptures of the anterior cruciate ligament: a 5-year follow-up. Acta Orthop Scand 1984;55:270-2.

Parker AW, Drez D Jr, Cooper JL. Anterior cruciate ligament injuries in patients with open physes. Am J Sports Med 1994;22:44-7.

Ryu RK, Dunbar WH. Arthroscopic meniscal repair with two-year follow-up: a clinical review. Arthroscopy 1988;4:168-73.

Satku K, Kumar VP, Ngoi SS. Anterior cruciate ligament injuries: to counsel or to operate? J Bone Joint Surg [Br] 1986;68-B:458-61.

Tegner Y, Lysholm J. Rating systems in the evaluation of knee ligament injuries. Clin Orthop 1985;198:43-9.

Vähäsarja V, Kinnuen $P$, Serlo $\mathbf{W}$. Arthroscopy of the acute traumatic knee in children: prospective study of 138 cases. Acta Orthop Scand 1993;64:580-2 